\title{
Lazer para todos? Análise de acessibilidade de alguns parques de Curitiba, $\mathbf{P R}^{1}$
}

\author{
Marina Redekop Cassapiana, Simone Rechiab \\ aUniversidade Federal do Paraná - UFPR, Curitiba, PR, Brasil \\ bepartamento de Educação Física, Universidade Federal do Paraná - UFPR, Curitiba, PR, Brasil
}

\begin{abstract}
Resumo: Este artigo busca refletir sobre a relação da acessibilidade de alguns espaços públicos de lazer de Curitiba com a garantia do direito ao lazer dos integrantes do grupo de cadeirantes A "União faz a Força". Para tanto, traçaram-se os seguintes objetivos específicos: identificar os espaços de lazer conhecidos pelo grupo "A União faz a Força"; analisar a acessibilidade desses espaços com um roteiro; e investigar as facilidades e dificuldades encontradas pelos integrantes do grupo no uso desses espaços sob o ponto de vista dos próprios usuários. Esta investigação foi desenvolvida a partir de uma abordagem qualitativa, sendo utilizada a estratégia de triangulação dos dados coletados em entrevistas semiestruturadas com pessoas cadeirantes, observação sistemática de quatro espaços de lazer da cidade, bem como dos passeios do grupo de cadeirantes realizados em dois parques com o referencial teórico. Destaca-se que, apesar de Curitiba possuir facilidades, ainda identificamos muitos problemas relacionados à acessibilidade, que reduzem a mobilidade da pessoa com deficiência na cidade e dificultam o acesso aos espaços de lazer. Também encontramos várias barreiras que impedem o uso dos equipamentos de lazer, como também o uso dos sanitários nos espaços públicos observados. Conclui-se, portanto, que a falta de acessibilidade encontrada nesses espaços e na mobilidade urbana de Curitiba reduzem a possibilidade de escolha do lazer e consequentemente restringem a garantia do direito ao lazer para os integrantes do grupo "A União faz a Força".
\end{abstract}

Palavras-chave: Desenvolvimento Urbano, Atividades de Lazer, Pessoas com Deficiência, Inclusão Social, Acessibilidade.

\section{Leisure for all? - accessibility analysis of some parks in Curitiba, Parana State}

\begin{abstract}
This article aims to reflect about the accessibility of some public spaces in Curitiba and the right to leisure of the members of a wheelchair users group called "A União faz a Força". To this end, the following specific objectives were established: identify leisure spaces known by the group "A União faz a Força"; analyze the accessibility of these spaces using a script; and investigate the facilities and difficulties encountered by the group members in using these leisure spaces. This investigation was developed based on a qualitative approach, using the triangulation of data collected in semi-structured interviews with wheelchair users, the systematic observation of four leisure spaces, as well as the rides taken by the group at the parks as theoretical referential. It is worth mentioning that, although Curitiba presents facilities, it also presents many difficulties related to accessibility, which reduce the mobility of disabled persons in the city and hinder their access to leisure installations. Observing the public spaces, we also found several obstacles that prevent the use of recreational equipment and restrooms. Therefore, it is possible to conclude that the lack of accessibility observed in these spaces and in the urban mobility in Curitiba reduces the choice of leisure and restricts the right to leisure for the members of the group "A União faz a Força".
\end{abstract}

Keywords: Urban Development, Leisure Activities, Disabled Persons, Social Inclusion, Accessibility.

Autor para correspondência: Marina Redekop Cassapian, Rua Quinze de Novembro, 1299, Centro, CEP 80060-000, Curitiba, PR, Brasil, e-mail: jmcassapa@gmail.com

Recebido em 4/5/2012; $1^{\text {a }}$ Revisão em 14/9/2012; $2^{\text {a }}$ Revisão em 7/11/2012; Aceito em 24/1/2013. 


\section{Introdução}

Atualmente, as cidades são entendidas para além de seus espaços geográficos e podem ser consideradas palcos da vida em sociedade, nos quais se estabelecem as relaçóes humanas. De tal forma que Borja (2005) sugere olharmos para a cidade como um espaço público que possibilita a convivência e o exercício da cidadania por todos os cidadãos.

De acordo com Rechia (2003), a cidade é uma organizaçấo viva e dinâmica e em constante modificação, pois necessita da interação entre diferentes espaços e equipamentos urbanos para favorecer a mobilidade urbana, bem como o uso e apropriação dos espaços públicos, a fim de proporcionar as relaçóes de troca entre todos os cidadãos.

Considerando a cidade um organismo dinâmico e público que possui espaços interligados, Consenza e Rezende (2006) destacam a necessidade da participação da população no planejamento urbano por meio das políticas públicas e também afirmam que as inadequaçóes dos espaços na cidade podem ser consideradas um desrespeito à diversidade humana, pois ferem o direito à apropriação da cidade, destacado por Lefebvre (2001).

O direito à cidade deve ser garantido para todas as camadas da população, independentemente das condiçôes sociais, econômicas ou de saúde. Ele vai além dos direitos sociais garantidos à população, como direito à saúde, moradia, lazer, entre outros, pois envolve o direito de participar das atividades da cidade e o direito à apropriação dela, ou seja, de se relacionar com os outros cidadãos e com os diversos equipamentos urbanos (LEFEBVRE, 2001). Essa apropriação, porém, precisa estar pautada nos princípios da cidadania e respeito à diversidade dos cidadãos que vivem na cidade, buscando a inclusão de todos.

Porém, ao olharmos para as cidades podemos perceber que ainda existem vários fatores que podem limitar o direito à ela, entre eles questôes relacionadas à falta de segurança, crescimento desordenado, dificuldades na mobilidade urbana, entre outros. Contudo, ao focarmos especificamente as pessoas com deficiência, observamos que ainda há barreiras nos diferentes espaços urbanos que dificultam o deslocamento e o uso da cidade e de seus espaços.

Ao longo dos últimos anos, diferentes áreas do conhecimento têm discutido sobre a inclusão das pessoas com deficiência ${ }^{2}$ e mobilidade reduzida ${ }^{3}$, bem como a necessidade de modificar os espaços sociais para torná-los acessíveis para todas as pessoas. Além disso, o próprio entendimento sobre as pessoas com deficiência e a inclusão delas na sociedade sofreu alteraçóes. Nos últimos anos, percebeu-se que, além da adaptação da própria pessoa com deficiência, havia a necessidade de adaptação da sociedade, já que as barreiras para a inclusão não se encontram apenas na deficiência, mas também em fatores externos à pessoa.

Alterou-se também o conceito de acessibilidade, que na década de 1990 integrou os princípios do Desenho Universal, voltados à criação de espaços para uso por todas as pessoas, independentemente de idade, presença de deficiência ou diferentes condiçôes de saúde.

Dessa maneira, utilizamos a definição apresentada na legislaçáo brasileira, que entende a acessibilidade como condição de uso de um espaço e de seus equipamentos com autonomia e segurança, principalmente por pessoas com mobilidade reduzida ou com alguma deficiência (BRASIL, 2004; ASSOCIAÇÃO..., 2004). Essa condição de uso é garantida pela eliminação das diferentes barreiras encontradas na cidade, as quais Dischinger et al. (2004, apud MORAES, 2007) ${ }^{4}$ classificaram como barreiras atitudinais, relacionadas ao preconceito com as pessoas diferentes; barreiras físicas, encontradas nos espaços, edifícios e transportes; e barreiras de informação, que dificultam a comunicação entre as pessoas e o uso dos equipamentos urbanos.

Observamos que essa definição relaciona a acessibilidade ao uso de um espaço específico e de seus equipamentos, entretanto salientamos a importância de se compreender a relação entre os diferentes espaços da cidade e a mobilidade urbana, já que primeiramente o indivíduo necessita conseguir sair de sua casa e locomover-se até o espaço para usá-lo.

Diante do exposto acima, remetemos nosso olhar sobre a cidade de Curitiba, PR, e questionamos: como se encontra a acessibilidade dos espaços de lazer? Rechia (2003) afirma que Curitiba tem sido referência para planejadores urbanos e arquitetos e é reconhecida como cidade-modelo e cidade planejada, uma vez que seus espaços públicos associam modernidade, lazer e cultura.

De acordo com Rechia (2003), o planejamento de Curitiba iniciou-se na década de 1940, com a instituição do Plano Agache ${ }^{5}$ que previa a preservação e o embelezamento do espaço urbano com a criação de parques públicos. Rechia (2003) aponta ainda a década de 1970 como marco de transformaçáo física, econômica, social e cultural da história de Curitiba. Nesse período, a cidade iniciou a tradição 
de preservar as áreas naturais para transformá-las em espaços públicos de lazer, com soluçôes urbanísticas funcionais e estéticas que forneceram à cidade uma marca identitária ${ }^{6}$.

Em 2004, tanto a adequação do plano diretor da cidade, pela lei n. 11.266/047, como a publicaçáo do decreto n. 5.296/04 e da Política de Acessibilidade do Ministério das Cidades impulsionaram reformas nos espaços para garantir a acessibilidade. De acordo com os jornais da cidade de Curitiba, foram realizadas várias reformas nos espaços de lazer, nas vias, calçadas e nos transportes.

Em 2010, Curitiba empreendeu alguns avanços voltados para inclusão das pessoas com deficiências com a criação da Secretaria Municipal Especial dos Direitos da Pessoa com Deficiência, cujos objetivos são promover açóes políticas e sociais, bem como facilitar articulaçôes intersetoriais relacionadas às questôes de inclusão das pessoas com deficiência e à acessibilidade (CURITIBA, 2010).

Apesar dessa marca positiva da cidade, alguns autores, como Moura $^{8}$ (2007, apud OLIVEIRA; RECHIA, 2009), demonstram que essa imagem de Curitiba é alvo de críticas dos próprios moradores da cidade, já que muitos deles, principalmente moradores de regiốes periféricas, não vivem essa realidade e enfrentam problemas de segurança, transporte, entre outras dificuldades presentes nas grandes cidades brasileiras.

Os apontamentos citados nos trazem algumas inquietaçôes, dentre elas se a cidade de Curitiba está planejada para todos os cidadáos, inclusive para as pessoas com deficiência motora, que representam $15,9 \%{ }^{9}$ da população da cidade. Essa parte da população usufrui do direito à cidade como direito supremo de todas as pessoas, independentemente de classe social, idade ou condição de saúde?

Entre os direitos sociais garantidos pela Constituição de 1988 encontramos o direito ao lazer, que apesar de ser considerado direito de todos os cidadãos, ainda não é usufruído por todos. Para Reis e Starepravo (2008), entre as barreiras que limitam a garantia desse direito encontra-se a falta de compreensão da importância do lazer, que acaba tornando esse um "direito de menor valor", se comparado aos outros direitos sociais. Outros obstáculos estão relacionados à disponibilização e ao acesso aos espaços e equipamentos de lazer.

Ao discutir o acesso aos espaços, os referidos autores apontam a desigualdade social, a precariedade de acesso, a privatização dos espaços, entre outras questôes ligadas à esfera econômica. Referente à acessibilidade dos espaços públicos de lazer no Brasil, perguntamos: como se encontra, considerando que os dados mais recentes do Instituto Brasileiro de Geografia e Estatística (IBGE), referentes ao censo do ano 2010, demonstram que existem aproximadamente 45,6 milhóes de pessoas com deficiência no Brasil (INSTITUTO..., 2012)?

De acordo com a literatura, ainda há carência de espaços de lazer acessíveis para as pessoas com deficiência nas diferentes cidades do Brasil. Entre os autores que desenvolveram estudos nessa área, encontramos Hunger, Squarcini e Pereira (2004), Burjato (2004), Resende (2004), Santos et al. (2006), Julião e Ikemoto (2006), Rezende et al. (2007), Bacil e Watzlawick (2007), Ribeiro et al. (2007), Araujo, Cândido e Leite (2009) e Melo et al. (2009). Esses estudos vão ao encontro da afirmação de Leite (2007), que aponta as barreiras arquitetônicas nos espaços como um dos maiores obstáculos para a inclusão das pessoas com deficiência.

Em Curitiba, a criaçáo da maioria dos parques ocorreu a partir da década de 1970, com objetivo de preservar-se a natureza. Cabe ressaltar, porém, que nesse período a sociedade possuía a compreensão de que a deficiência estava centrada apenas na pessoa e que essa deveria ser reabilitada para conseguir viver na sociedade. Somente a partir da década de 1980 as barreiras físicas começaram a ser consideradas como obstáculos para a inclusão das pessoas com deficiência, desde então ocorreram várias açôes, entre elas podemos citar a criaçáo de uma Política Nacional de Acessibilidade e a elaboração de leis e normas voltadas para eliminação dessas barreiras.

Para tanto, nos propomos investigar a acessibilidade de alguns espaços públicos de lazer da cidade de Curitiba, PR, e traçamos os seguintes objetivos específicos: analisar esses espaços utilizando um roteiro baseado na Norma Brasileira de Acessibilidade (NBR-9050) e no protocolo de acessibilidade do Conselho Regional de Engenharia e Arquitetura do Paraná (CREA-PR); investigar as facilidades e dificuldades encontradas pelos integrantes do grupo de cadeirantes A União faz a Força para utilização dos espaços de lazer, sob o ponto de vista dos próprios usuários.

\section{Metodologia}

Para a realização desta pesquisa de cunho sociológico e exploratória utilizamos a abordagem qualitativa e adotamos a estratégia de triangulação com diferentes técnicas de coleta de dados, as quais, conforme Flick (2009b, p. 362), têm como objetivo "enriquecer e complementar ainda 
mais o conhecimento e [...] superar os potenciais epistemológicos (sempre limitados) do método individual".

Adotamos o lema utilizado na luta das pessoas com deficiência: Nada sobre nós, sem nós, e, portanto, convidamos os quatro integrantes do grupo de cadeirantes A Uniāo faz a Força ${ }^{10}$ para participarem da pesquisa.

Como critério de inclusão, adotamos a participação dos cadeirantes no grupo supracitado durante o ano de 2010, sendo os critérios de inclusão para participação no grupo: não possuir graves comprometimentos cognitivos que prejudicassem a compreensão da proposta e ter autonomia mínima na locomoção na comunidade.

A coleta de dados se deu por meio de entrevistas semiestruturadas com os cadeirantes, observação sistemática de quatro espaços de lazer, observaçáo de dois passeios realizados pelo grupo de cadeirantes. Iniciamos com as entrevistas semiestruturadas com os quatro cadeirantes que, segundo Alves-Mazzoti e Gewandsznajder (2004), permitem explorar temas complexos com mais profundidade para, dessa forma, compreender como os cadeirantes entendem a questão da acessibilidade dos espaços públicos de lazer de Curitiba, PR.

Após as entrevistas, foram realizadas observações sistemáticas de quatro espaços públicos de lazer, para fazer-se a análise de acessibilidade. O critério de escolha dos espaços foi: analisar espaços públicos de lazer que o grupo havia conhecido durante os passeios realizados entre os anos de 2008 e 2010 e um parque, criado em 2008, que é considerado pela gestão pública como adaptado às pessoas com deficiência. A observação sistemática, segundo Marconi e Lakatos (2003) e Gil (1999), prevê a utilização de um instrumento regulador utilizado para identificar categorias de observação relevantes - para esta pesquisa foi utilizado um roteiro criado pelas pesquisadoras ${ }^{11}$ para avaliar a acessibilidade das seguintes categorias: acesso (entrada e estacionamento), circulaçáo e uso do espaço e dos equipamentos de lazer e sanitários. Os espaços públicos de lazer avaliados com o roteiro foram o Parque Barigui, o Parque Bacacheri e a Unilivre e o Parque Lago Azul, sendo realizada uma visita a cada espaço.

Realizamos ainda observaçôes de duas atividades externas realizadas pelo grupo, que foram passeios acompanhados $^{12}$ a um espaço de lazer escolhido pelos próprios integrantes do grupo. Durante o período da pesquisa, o grupo realizou um passeio ao Parque Bacacheri ${ }^{13}$ e à Unilivre ${ }^{14}$, sendo que cada passeio teve duraçáo de quatro horas. O registro das observaçóes foi feito através de registro fotográfico, filmagem e anotaçóes em diário de campo, com as seguintes categorias: dificuldades e facilidades no deslocamento, acesso e uso dos espaços e dos equipamentos.

Quanto à análise dos dados, foi de cunho interpretativo e preocupou-se em compreender as dificuldades e facilidades na acessibilidade dos espaços públicos de lazer de Curitiba conhecidos pelo grupo A Uniáo faz a Força, bem como qual a relação entre a acessibilidade e a garantia do direito ao lazer para os integrantes do grupo. Logo, iniciamos com a análise das entrevistas com as pessoas cadeirantes, que nos apontaram as categorias de análise a partir dos temas principais levantados (FLICK, 2009a). Seguimos então com as observações dos espaços e as vivências.

Com esse procedimento encontramos as seguintes categorias de análise: acessibilidade da cidade de Curitiba, PR, relacionada à mobilidade, subdividida em transportes e calçadas; acessibilidade dos espaços de lazer, relacionada a facilidades de uso e dificuldades de uso; e o lazer.

A interpretação foi realizada através da triangulaçáo dos dados verbais e visuais coletados com o referencial teórico, para permitir uma análise mais aprofundada dos fatos (FLICK, 2009a).

\subsection{A acessibilidade dos espaços públicos de lazer estudados}

Ao serem questionados sobre a sua compreensão de acessibilidade, todos os cadeirantes mencionaram o direito a se locomoverem de forma independente. Essa relação direta entre mobilidade para o uso dos espaços da cidade e a acessibilidade também é mencionada pelo Ministério das Cidades (2006, p.11):

Para as pessoas com restrição de mobilidade ter acessibilidade náo se resume à possibilidade de entrar em um determinado local ou veículo, mas na capacidade de se deslocar pela cidade, através da utilização dos vários modos possíveis de transporte, organizados em uma rede de serviços e por todos os espaços públicos, de maneira independente.

Apesar de Curitiba ser conhecida como cidade planejada e ter tido vários avanços voltados à inclusão das pessoas com deficiência, como possuir mais de $80 \%$ da frota de transporte adaptada, os cadeirantes apontaram muitas barreiras nos transportes urbanos, entre elas elevadores de ônibus sem manutenção, locais onde ainda não há transporte público adaptado, 
demora na espera por transporte adaptado, como pode ser observado nas falas a seguir:

tem vez que o elevador do ônibus não funciona e também tem os elevadores dos tubos que não funcionam. Eainda assim pessoa que está comigo, me acompanhando, tem que pagar mesmo o elevador estando estragado. (CADEIRANTE 2)

\section{Sempre tenho que ficar pedindo ajuda para} alguém, ou para subir ou para descer. Consigo usar o ônibus quando é o ônibus ligeirão e ligeirinho, sim, pois eles já têm as rampas próprias. Mas quando tenho que usar ônibus com elevador, como no caso do bairro em que eu moro, dai o problema é sério. Às vezes tem o ônibus, às vezes a rampa [elevador] está estragada. O ponto de ônibus também não está adequado. Muitas vezes o motorista passa e deixa a pessoa no ponto. Às vezes está no horário que tem o ônibus, mas o ônibus não está na linha.

\section{(CADEIRANTE 3)}

Muitos dos tubos de ônibus têm elevadores, mas não estão funcionando, às vezes o tubo do ônibus está com elevador estragado. (CADEIRANTE 4)

Já obstáculos encontrados no deslocamento pelas calçadas foram tantos que em algumas situaçôes os cadeirantes somente conseguiram andar pela rua, entre os carros, arriscando a própria segurança, como afirmam os cadeirantes:

Para mim o ruim são as calçadas. As calçadas são a pior coisa que tem. Prefiro mil vezes andar na rua. (CADEIRANTE 1)

Tem vez que não tem rampa para você chegar ao local. Tem muitos buracos, a calçada é ruim, calçada muito ruim. Principalmente lá no Centro. $E$ Edificil. Como vou andar sozinho no Centro com aquelas calçadas todas ruins? Alguns lugares, não vou dizer que são todos. Alguns lugares, sim, são ótimos. Mas a maioria está péssima, péssima mesmo. (CADEIRANTE 2)

Outro fato relevante apontado por dois cadeirantes é que só podem ir a lugares que conhecem antecipadamente, em função das possibilidades de acesso, como aponta um dos cadeirantes:

Eu não tenho coragem de sair sozinha e também não tenho companhia. E para eu sair sozinha, como eu falei, tenho muitas dificuldades, não tenho como subir degraus. (CADEIRANTE 4)
Eles ainda destacaram que não existem muitas informaçóes sobre a adaptação dos espaços nos diferentes meios de comunicaçáo da cidade, o que os impede de conhecerem espaços novos, como afirma a cadeirante 3:

[...] por exemplo, onde eu ando mais tenho o costume de ir sozinha, saio sem ficar pensando. Aonde [sic] eu não conheço, não vou. (CADEIRANTE 3)

Quanto à análise dos quatro espaços públicos de lazer, a partir do roteiro de acessibilidade, observamos muitas semelhanças nos equipamentos, bem como no tipo de barreiras físicas encontradas, principalmente entre o Parque Barigui e o Parque Bacacheri, ambos criados antes da década de 1990 , período em que não se tinha uma compreensão ampla da necessidade de criação de espaços para todos. Além disso, analisamos, por meio da triangulação, as dificuldades e facilidades no uso dos espaços de lazer sob o ponto de vista dos cadeirantes. Identificamos que as barreiras encontradas na observação dos espaços foram semelhantes àquelas notadas durante os passeios, como também às apontadas pelos cadeirantes. Apesar da possibilidade de chegar a todos os espaços com ônibus adaptados, encontramos vários obstáculos no acesso. No entorno de três espaços (Parque Barigui, Parque Bacacheri e Unilivre) detectamos a ausência de guias rebaixadas, falta de calçamento, além de distância náo apropriada do ponto de ônibus até a entrada do parque. Apenas o Parque Barigui apresentou guias rebaixadas em uma das entradas. Em relaçáo às dificuldades de acesso citadas pelos cadeirantes, eles destacaram: o transporte e as condiçóes das calçadas da cidade, que ainda encontram-se em condições precárias, como já citado anteriormente.

Quanto à presença de vagas de estacionamento reservadas, foram encontradas em três espaços de lazer, contudo um parque apresentou algumas vagas com dimensôes abaixo das determinadas nas normas e outro apresentava um obstáculo para evitar o uso da vaga por pessoas sem deficiência, mas que também limitava a independência no uso da vaga pelas pessoas com deficiência ou mobilidade reduzida (Figura 1).

Já as facilidades apontadas pelos cadeirantes relacionavam-se à circulação nos espaços de lazer nos três parques, pois esses possuem pista de caminhada com piso estável, no entanto na Unilivre identificamos a presença de piso instável em praticamente todo o parque, o que interfere no deslocamento, segurança e autonomia dos cadeirantes, além de na própria apropriação do espaço (Figura 2): 


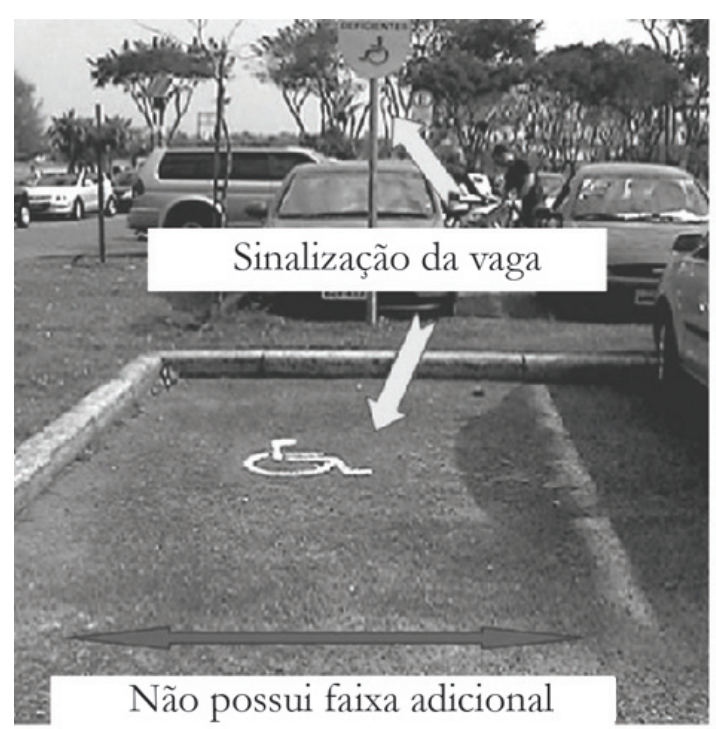

Parque Barigui

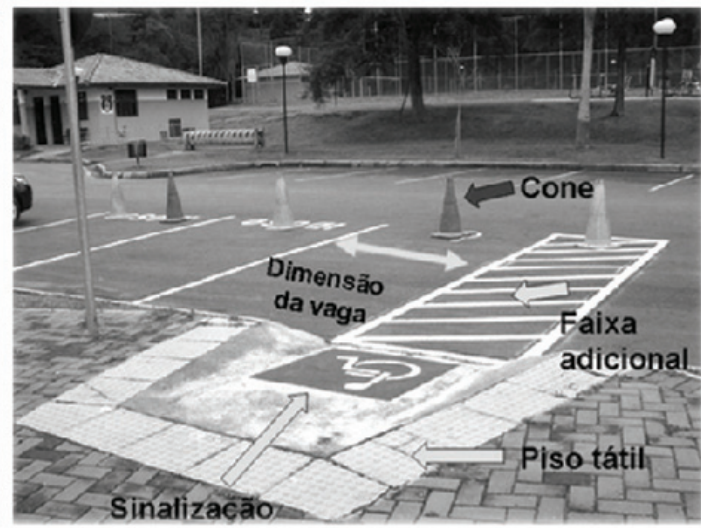

Parque Lago Azul

Figura 1. Vagas de estacionamento reservadas para pessoas com deficiência.

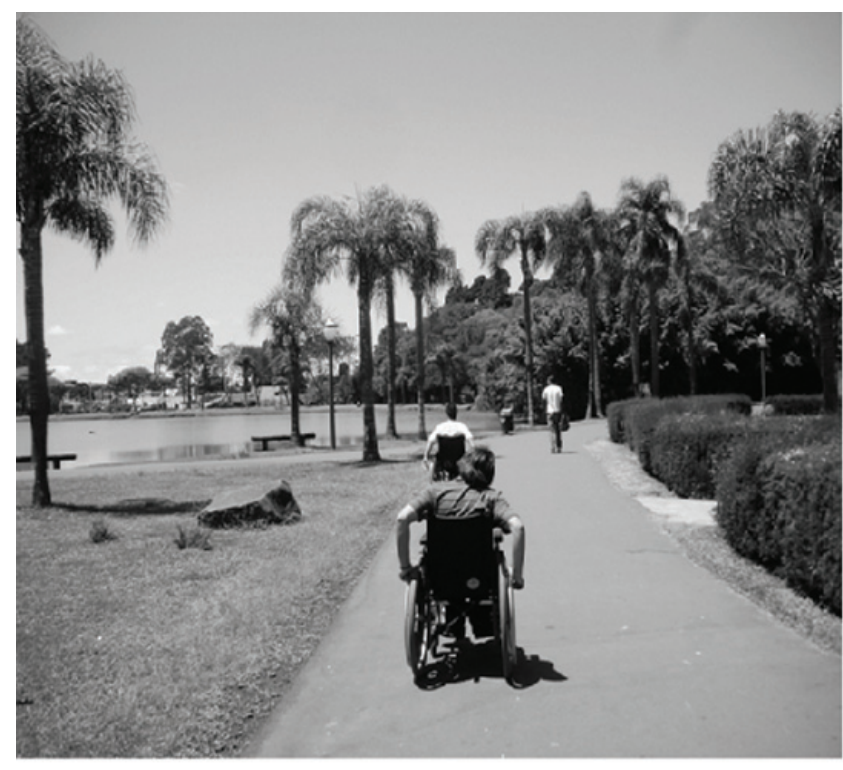

Parque Bacacheri piso estável

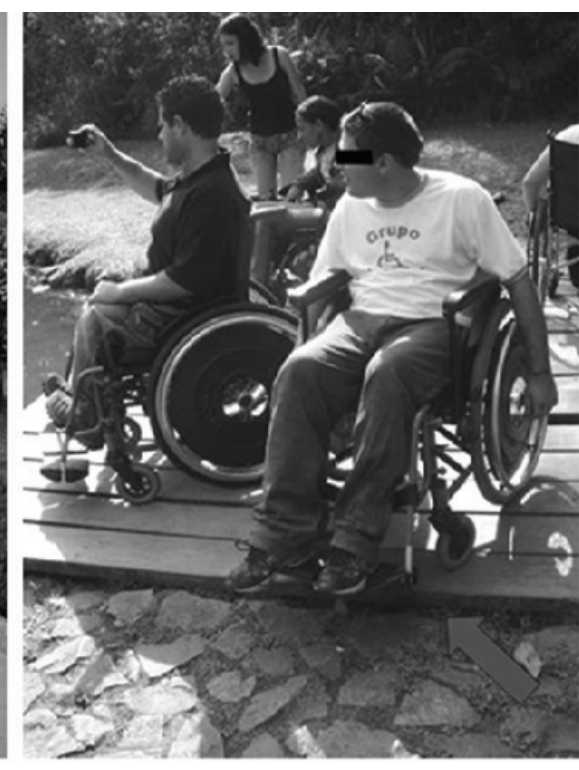

Unilivre piso instável

Figura 2. Circulação nos espaços de lazer.

Facilidade é a parte da calçada que é fácil nos locais, a entrada dos locais também. (CADEIRANTE 2)

Muitas vezes tem facilidades. Tem aquelas guias de ciclista. Pista de caminhada. Dependendo do local, tem o rebaixamento correto. (CADEIRANTE 3)
No Parque Barigui encontramos barreiras na circulação, com escadas no acesso às pontes que ligam os dois lados do parque.

Também encontramos barreiras no acesso e uso de praticamente todos os equipamentos dos quatro espaços analisados. Nos parques Barigui e Bacacheri detectamos que o acesso aos equipamentos 
geralmente se dá por um piso de grama e observamos desníveis entre os pisos, além de degraus e desníveis no acesso às canchas de esporte, aos equipamentos de ginástica, ao playground e às churrasqueiras, entre outros. Também notamos a presença de piso instável em todos os equipamentos, além de nenhum dos equipamentos voltados à recreação infantil e às atividades físicas permitir o seu uso por pessoas com deficiência, por năo estarem adaptados (Figura 3). Isso também foi pontuado:

Há uma carência de equipamentos acessiveis para as pessoas com deficiência nos parques de Curitiba. (CADEIRANTE 3)

As mesmas barreiras também foram observadas no Parque Lago Azul, inaugurado em 2007. Cabe, porém, salientar que no ano de criação do parque já vigorava o decreto n. 5.296/04, que determina que todos os espaços construídos sejam acessíveis. Percebemos que a acessibilidade foi realizada somente nos edifícios construídos, como, por exemplo, no bistrô, mas que os equipamentos do parque ainda apresentam barreiras físicas. Ressaltamos que já foi comprovado por Reis e Lay (2010) que o custo de adaptação é maior que o custo de construçáo do espaço acessível. Assim, podemos notar que a acessibilidade ainda não é considerada prioridade na construção e renovação de equipamentos. Fato esse também comprovado na observação do Parque Bacacheri, pois esse passou por reforma em 2008 e ainda năo possui sanitário adaptado para pessoas com deficiência.

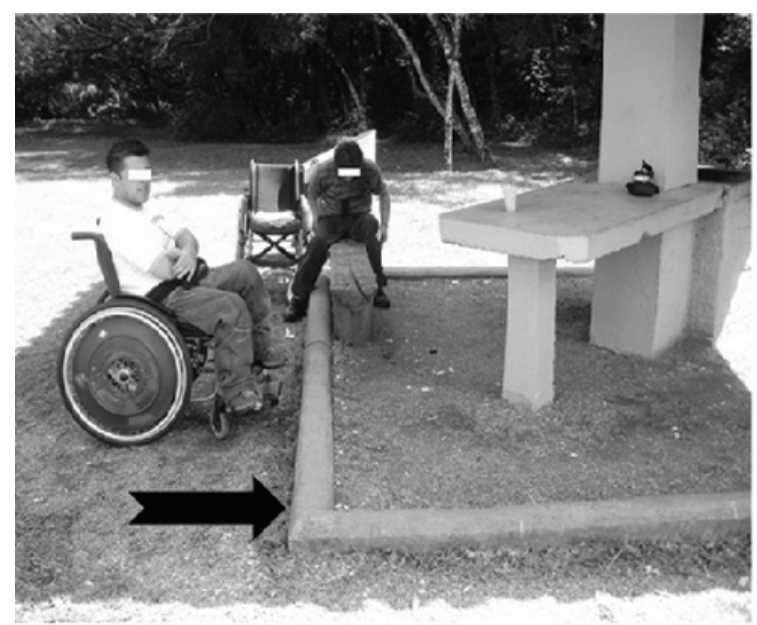

$$
\begin{aligned}
& \text { Parque Bacacheri } \\
& \text { churrasqueira }
\end{aligned}
$$

Quanto aos sanitários, podemos afirmar que na Unilivre, no Parque Bacacheri e nos quatro módulos de sanitários do Parque Barigui, as adaptaçóes, quando encontradas, não condizem com a norma, portanto esses não podem ser considerados sanitários adaptados (Figura 4).

No Parque Barigui há um sanitário adaptado próximo às salas do Instituto Municipal de Administração Pública (IMAP), mas não há sinalização que indique a sua localização para os frequentadores. Já no Parque Lago Azul havia um sanitário totalmente adaptado conforme a norma, no entanto estava trancado, ou seja, havia uma barreira criada pela própria administraçáo do local.

Os cadeirantes também destacaram a falta de adaptação nos sanitários:

Banheiro até agora eu não encontrei nenhum que pudesse usar. Quando a porta não é estreita, é larga mas não tem as barras, ou não são adequadas para minha deficiência. Não está adaptada à minha necessidade. A pia eu consigo usar. (CADEIRANTE 3)

Os banheiros, que nem na Unilivre, que não têm espaço para cadeira de rodas, não tem como chegar até a porta, não têm as barras. Não são acessiveis. (CADEIRANTE 4)

Logo, detectamos barreiras tanto no entorno quanto nos espaços e equipamentos, as quais dificultam o acesso e a sua utilização, diminuindo

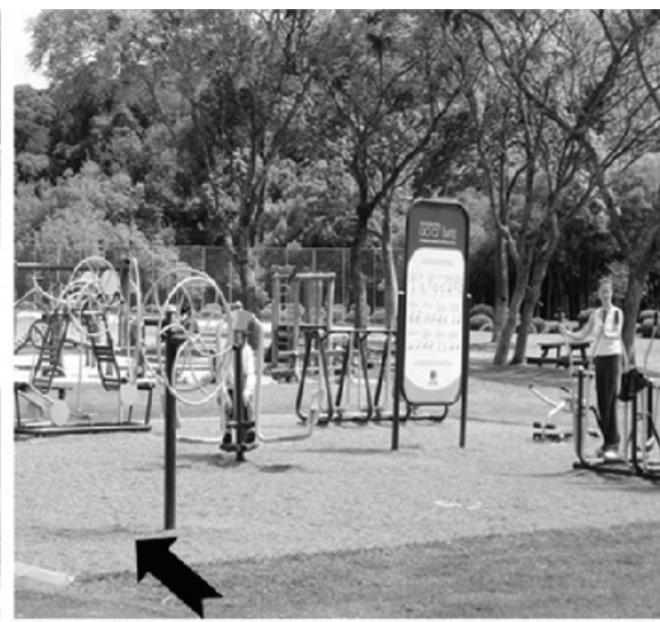

Parque Bacacheri academia de idoso

Figura 3. Barreiras encontradas no acesso aos equipamentos nos espaços de lazer. 


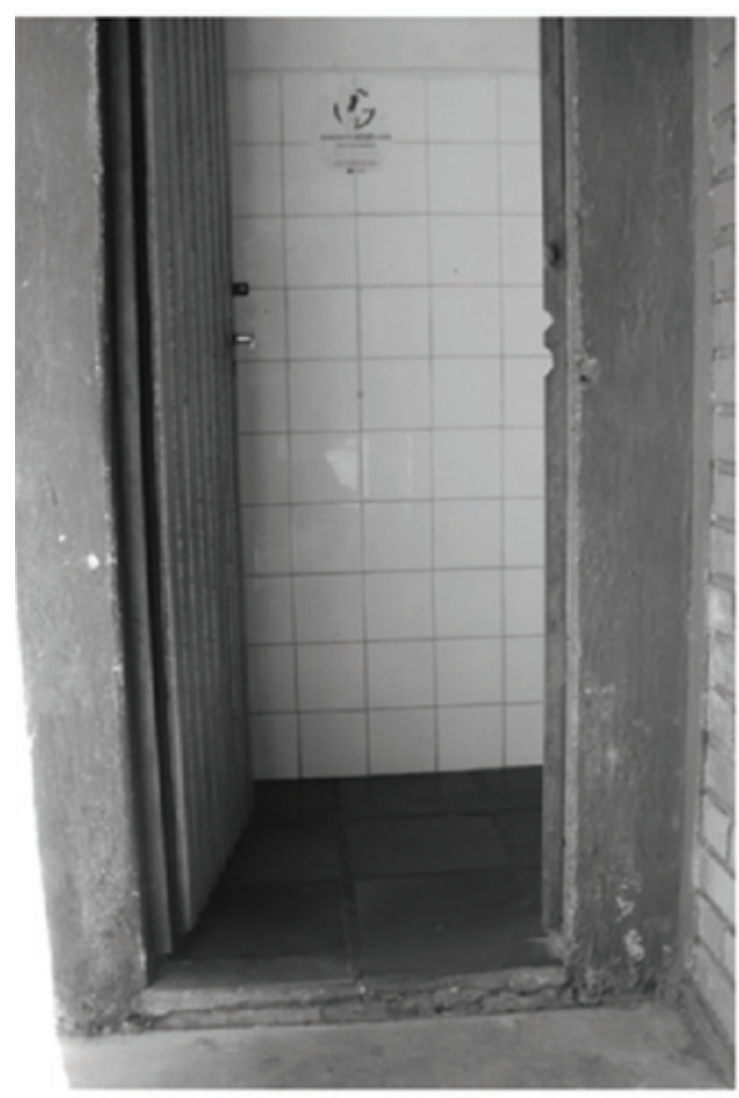

\section{Entrada do sanitário com degrau}

Figura 4. Sanitários não adaptados.

consequentemente as possibilidades de escolha no tempo/espaço de lazer para os cadeirantes.

\subsection{O direito ao lazer: conexão entre atitude, tempo e espaço}

O lazer é um fenômeno discutido por diversas outras áreas do conhecimento, o que o torna um campo complexo, com diferentes concepçóes. Muitos autores compreendem o lazer como um fenômeno da sociedade moderna e relacionam o seu surgimento com o período da Revolução Industrial, sendo ele considerado um direito social conquistado pelos trabalhadores, que possuíam uma carga elevada de trabalho.
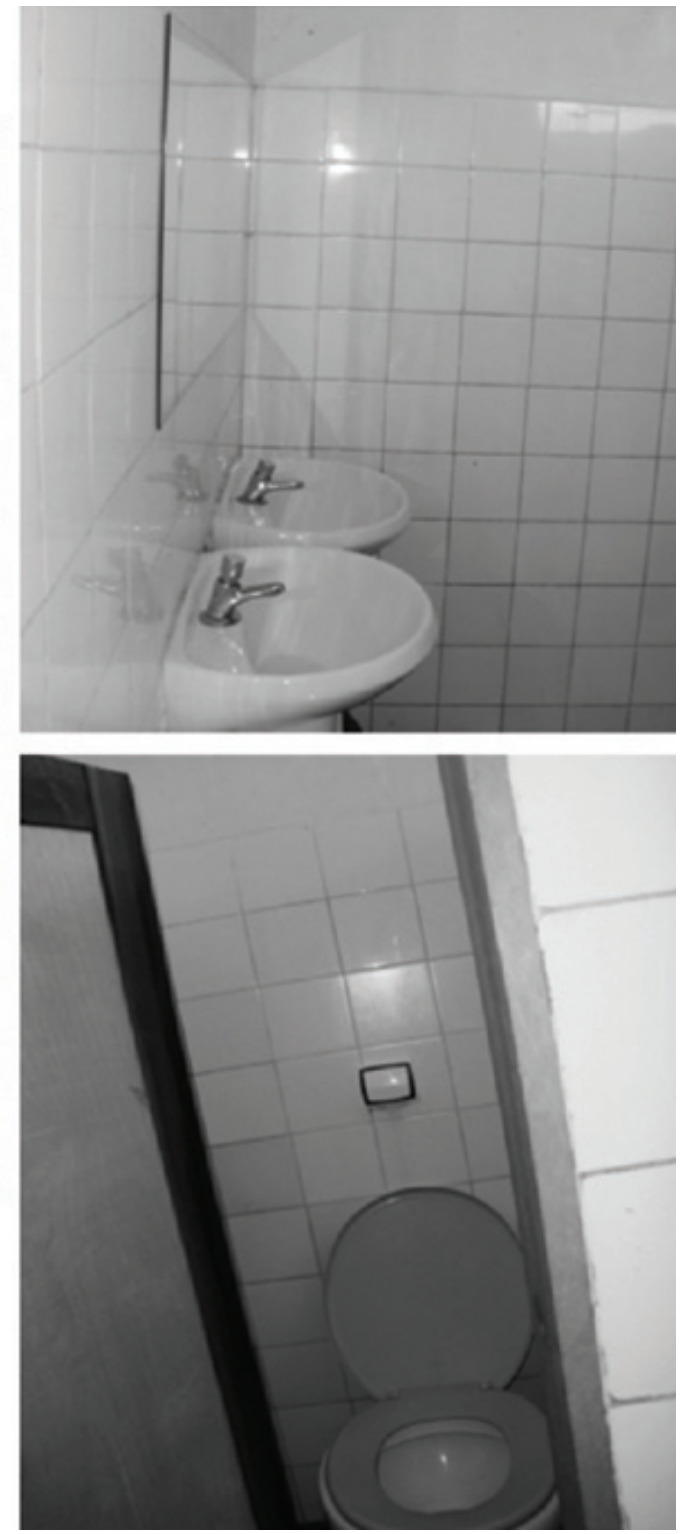

Essa conquista do direito ao tempo livre pelos trabalhadores não deve ser desmerecida, entretanto Gomes (2008) destaca que o lazer não deve ser discutido apenas pela categoria tempo, já que garantia do tempo livre não garante uma vivência significativa de lazer.

Entre os diversos conceitos de lazer, Mascarenhas (2004, p. 97) o define como

um fenômeno tipicamente moderno, resultante das tensóes entre capital e trabalho, que se materializa como um tempo e espaço de vivências lúdicas, lugar de organização da cultura, perpassado por relaçóes de hegemonia. 
Nesse conceito encontramos a relação tempo de lazer com tempo de trabalho, bem como a sua relação com a cultura e o lúdico, além das categorias tempo e espaço. Mascarenhas (2004) aponta que o lazer não pode ser visto de maneira isolada e concorda com Gomes (2008) sobre a necessidade de se conhecer o contexto em que ocorre, pois esse pode mascarar as condiçóes sociais devido à presença das relaçôes de hegemonia. Além disso, Gomes (2008) acrescenta que o tempo/espaço de lazer pode também representar uma possibilidade de questionamento à ordem existente, ou seja, um tempo e espaço para o exercício da cidadania.

De acordo com as entrevistas com os cadeirantes, o lazer está relacionado à diversão e nos remete aos benefícios apresentados pela Carta Internacional de Educação para o Lazer, como satisfação, diversão, prazer e aumento de felicidade.

Vários autores, entre eles Knox (2002) e Cavalcanti (2007), também destacam o lazer como fenômeno inclusivo, por possibilitar o desenvolvimento de relaçóes sociais para as pessoas com deficiência. Nas entrevistas, um cadeirante aponta a inclusão pelo lazer ao citar a superação das barreiras, mas ele também destaca que a superaçáo não é total. Acreditamos que as barreiras relacionadas à própria deficiência possam ser diminuídas com a adaptação das atividades realizadas, já a eliminação das barreiras atitudinais e arquitetônicas depende, segundo Bartalotti (2006), de uma modificaçáo da sociedade e não da pessoa com deficiência.

Dentre os integrantes do grupo A União faz a Força, quando questionados sobre o que realizam em seu tempo/espaço de lazer, dois cadeirantes que sofreram lesão quando jovens relatam uma mudança nas possibilidades de escolha de lazer, que foram limitadas pela deficiência, pois antes da lesão praticavam atividades físicas e esportivas, como jogar futebol, andar de bicicleta, andar a cavalo, nadar, ir à praia, entre outras. Após a lesão, as possibilidades de lazer modificaram-se, restringindo-se à atividade passear.

Já os dois cadeirantes que nasceram com deficiência relatam com mais tranquilidade o fato de permanecerem a maior parte do tempo em casa, pois não tiveram experiências motoras relacionadas ao movimento corporal, portanto não têm lembranças e saudades dessas escolhas. Percebemos que a falta de experiência motora pode ter limitado as possibilidades de escolhas diversificadas de atividades no âmbito do lazer para esses dois cadeirantes.

Quando questionados sobre quais espaços de lazer cada um deles frequenta, os cadeirantes citaram os espaços que conheceram nos passeios realizados pelo grupo, além deles mencionaram alguns outros espaços. Cabe também ressaltar que relataram a presença de barreiras na maioria desses locais e não conseguiram informar uma periodicidade no uso desses espaços de lazer. Apenas um cadeirante informou que gosta de ir a parques nos finais de semana. Por tudo isso, intuímos que apesar de morarem em uma cidade que possui o planejamento voltado para as áreas culturais e de lazer, os integrantes do grupo conhecem apenas alguns poucos espaços de lazer da cidade de Curitiba e, além disso, não usam com frequência esses espaços. O que nos leva a refletir se há uma relação entre as barreiras físicas encontradas na cidade e nos seus espaços públicos e a frequência de uso desses espaços, visto que uma das cadeirantes afirmou:

Eu gosto de passear, mas não saio muito assim. Mas eu gosto. Eu não saio muito, mas saio. $\dot{E}$ meio difícil, pois lá perto de casa não é tudo adaptado. (CADEIRANTE 4)

A fala mostra que as barreiras físicas existentes na cidade interferem sim na participação das pessoas, em suas atividades, e limitam as possibilidades de lazer das pessoas com deficiência. O que aponta para a necessidade, como afirmam Consenza e Resende (2006), da organização das cidades ser realizada com um olhar inclusivo, para possibilitar às pessoas com deficiência exercerem sua cidadania.

Entendemos entâo que as barreiras encontradas na cidade podem ser impedimentos para o exercício do direito ao lazer pelas pessoas com deficiência. E, segundo Knox (2002) e Cavalcanti (2007), as restrições de participação no lazer, seja pelo contexto ambiental ou pelas limitaçóes específicas de cada indivíduo, podem afetar a autoestima, o bem-estar e o convívio social das pessoas com deficiência.

Diante da constataçáo da presença de diversas barreiras, tanto na cidade de Curitiba, PR, quanto nos espaços de lazer estudados, buscamos identificar o que os integrantes do grupo realizam nos espaços públicos de lazer quando conseguem chegar. Eles citaram a convivência com outras pessoas, o que nos remete à importância do espaço público que tanto Negt (2002) quanto Rechia e Betrán (2010) destacam como espaço que possibilita a socialização e convivência com outras pessoas e com culturas diferentes. Essa possibilidade de convívio com a diversidade auxilia, de acordo com Bartalotti (2006), na diminuição do preconceito e na aceitação do diferente.

O cadeirante 2 também pontua a satisfação, o prazer, a brincadeira e o lúdico como características 
que presentes em seu tempo/espaço de lazer. A vivência do lúdico, segundo Gomes (2008), permite experimentar uma sensação de liberdade e autonomia. Novamente observamos que não há uma frequência na realização dessas atividades lúdicas e acreditamos que isso se deva à presença das barreiras físicas na cidade, que dificultam o acesso aos espaços de lazer.

Além de possibilitar a convivência, a realização de atividades lúdicas, corporais e esportivas, Rechia (2003) também afirma que os espaços públicos de lazer da cidade de Curitiba permitem a aproximaçáo da natureza. Detectamos que para três integrantes do grupo estudado existe apenas essa possibilidade, como podemos observar na fala a seguir:

Eu gosto de ficar olhando a paisagem, observando, vendo as pessoas, fazer piquenique que a gente faz com o grupo. (CADEIRANTE 3 )

Novamente entendemos que a possibilidade de escolha dos cadeirantes foi restringida pela presença das barreiras físicas, já que a cadeirante 3 também relata interesse em realizar atividades físicas. Ela comenta que:

Não uso equipamento porque não é adaptado para o deficiente usar. Agora que tem aqueles equipamentos para fazer exercícios físicos [academia do idoso], en gostaria de usar, mas não tem como eu usar. [...] Para a pessoa com deficiência não tem muito que fazer. É só ir $e$ olhar e ficar olhando. Tudo tem barreira para entrar, muitas vezes não está adaptado. (CADEIRANTE 3)

A fala da cadeirante 3 demonstra que há interesse porém impossibilidade de realizar outras atividades. Após a análise dos espaços de lazer estudados, concordamos com a cadeirante, já que identificamos barreiras na maioria dos equipamentos existentes, como degraus nas entradas, piso instável e equipamentos para a prática de atividades físicas que não permitem o seu uso por pessoas cadeirantes. Zuchetto e Castro (2002) também relataram limitação das pessoas com deficiência física frente à realização de atividades físicas pela necessidade de adequaçóes dos equipamentos.

Desse modo, recorremos a Marcellino (2006), que aponta a eliminação das barreiras nos espaços como uma maneira de democratizar o lazer. O autor complementa que há necessidade de conhecer a população, ou seja, suas limitaçóes e suas capacidades, para que os equipamentos sejam realmente utilizados e tornem-se significativos para ela. Já Reis e Starepravo (2008) afirmam que a democratizaçáo do lazer somente ocorrerá pela efetivação das políticas públicas voltadas para a educaçáo do lazer, disponibilidade e localização dos espaços e sua acessibilidade. Entretanto, para que isso se materialize, faz-se necessária a participaçáo das pessoas com deficiência e/ou seus representantes na elaboração e implantação das políticas públicas.

Portanto, se considerarmos a contemplação e a aproximação da natureza como funções dos espaços públicos de lazer, podemos afirmar que as condições de circulação dentro dos espaços de lazer estudados, exceto na Unilivre, facilitaram a contemplação da natureza, entretanto ressalvamos que os cadeirantes enfrentaram várias barreiras para chegar aos espaços de lazer. Além disso destacamos que as experiências ruins, como no caso da Unilivre, podem diminuir o uso dos espaços, como afirmam Duarte e Cohen (2010).

Dessa maneira, destacamos a necessidade discutida por Rechia (2009), Reis e Starepravo (2008) e Castellani Filho (2006) de as políticas públicas de lazer estarem interrelacionadas com as questôes de planejamento urbano, bem como com as questôes sociais presentes na cidade. Acreditamos que somente dessa forma será possível a democratização do lazer e, consequentemente, dos espaços que possibilitam a inclusão dos diferentes cidadáos, como também o direito ao lazer para todas as pessoas.

\section{Considerações finais}

A acessibilidade é um tema que se encontra em pauta nas diferentes cidades do Brasil, pela necessidade de se adequarem os espaços, considerando a diversidade existente entre as pessoas. A partir da década de 1980, muitos avanços foram observados, principalmente como consequência da criação de leis e decretos voltados para as pessoas com deficiência.

A criação de um Programa Nacional de Acessibilidade realizada pelo Ministério das Cidades auxiliou a implementação do decreto $\mathrm{n}$. 5.296/04, que norteou as açóes voltadas para a melhoria e construção de cidades acessíveis. Apesar de esse decreto ter estipulado prazos para reformas e adaptaçóes dos espaços públicos das cidades e de os diversos estudiosos apontarem a necessidade de transformaçáo da sociedade, bem como dos seus espaços para possibilitar a inclusão das pessoas com deficiência, vários autores estudados demonstram que ainda há muitos espaços excludentes.

Para os autores que utilizamos na discussão do planejamento urbano, os espaços públicos das cidades, entre eles os espaços de lazer, possibilitam a convivência dos diferentes cidadáos e, 
consequentemente, a aproximação com o "diferente", sendo considerados locais de representação social. Assim, compreendemos que a exclusão das pessoas com deficiência dos espaços públicos fere o seu direito ao uso da cidade e impede o exercício de sua cidadania e, por conseguinte, o seu direito ao lazer.

Diante disso, investigamos se a acessibilidade dos espaços públicos de lazer estudados garante o direito ao lazer para o grupo de cadeirantes A União faz a Força, para o que acompanhamos o grupo nos passeios ao Parque Bacacheri e à Unilivre.

Primeiramente identificamos quais espaços de lazer os integrantes do grupo de cadeirantes conheciam. Embora eles tenham citado vários espaços de lazer da cidade de Curitiba, observou-se que a maioria deles conhece, de fato, apenas os espaços visitados nos passeios realizados pelo grupo, pois mencionaram não terem regularidade no uso de tais ambientes.

Essa falta de regularidade está relacionada com diversos fatores, mas percebemos, a partir da análise da estrutura dos espaços, que um dos fatores são as barreiras arquitetônicas, pois são barreiras físicas difíceis de serem superadas. Notamos, na fala dos entrevistados, que isso limita a independência e autonomia dos cadeirantes, tanto para chegar aos espaços quanto no uso regular deles, já que nenhum dos participantes do nosso estudo apresenta frequência no uso desses espaços. Isso nos confirma a necessidade da implantação de políticas públicas voltadas ao esporte e ao lazer para essas pessoas, com a apresentação de novos programas, bem como a questão da necessidade de adaptação dos equipamentos para aumentar as possibilidades de lazer dessa população.

$\mathrm{Na}$ análise dos espaços, bem como das dificuldades apontadas pelos cadeirantes, observamos barreiras tanto no entorno quanto nos espaços e equipamentos, as quais dificultam o acesso e a sua utilização e, consequentemente, diminuem as possibilidades de escolha no tempo/espaço de lazer para os cadeirantes.

Assim sendo, ressaltamos que apesar de a cidade de Curitiba, PR, apresentar avanços, como uma secretaria especial voltada para as questôes das pessoas com deficiência, e ter grande parte da frota de ônibus adaptada com rampas e elevadores, ainda identificamos muitos problemas relacionados à acessibilidade, os quais reduzem a mobilidade da pessoa com deficiência, com total autonomia e independência, na cidade. Acreditamos que os obstáculos encontrados na cidade induzem as pessoas com deficiência a permanecerem isoladas em sua residência e a não usufruírem do direito à cidade, ou seja, a não usufruírem de seus espaços, da convivência com outras pessoas e do exercício de sua cidadania.

Destacamos, portanto, a necessidade de olharmos para a cidade como uma organização viva que necessita ser renovada para atender a todas as camadas da população, sendo as questốes relacionadas à melhoria da mobilidade urbana primordiais para que as pessoas se desloquem e se apropriem dos espaços da cidade, de forma a compreendê-la como uma obra que pertence a e possui um significado para cada cidadáo e não apenas como um aglomerado de espaços não adaptados.

Dessa maneira, ressaltamos a importância de políticas públicas voltadas parra garantia de uma cidade para todos, pois, como afirma Borja (2006, p. 12, apud RECHIA; BETRÁN, 2010, p. 199),

[...] investir na qualidade do espaço público, de seu desenho, de seu enriquecimento e de sua manutenção nunca será um luxo, senão justiça democrática.

Identificamos que os integrantes desse grupo possuem o tempo para realizar atividades no âmbito do lazer, já que, dos quatro integrantes, apenas um estuda e nenhum deles trabalha. No entanto, o espaço, por não ser baseado nos princípios do Desenho Universal e apresentar as diversas barreiras discutidas nesta pesquisa, tanto no acesso quanto no uso, limita as possibilidades do grupo e, consequentemente, a potencializaçáo de novas experiências.

Também identificamos que o acesso a novas experiências no âmbito do lazer é limitado para os integrantes desse grupo, seja pelo fato de terem nascido com a deficiência e não terem tido acesso a vivências diversificadas, principalmente as esportivas, seja pelo fato de não conhecerem outras e novas possibilidades de lazer, como teatro, cinema, restaurantes, bares, entre outros, porque, simplesmente, não conseguem chegar até elas. Essa questão aponta para a necessidade de políticas públicas voltadas para a educaçáo pelo e para o lazer, possibilitando mais autonomia e independência aos cadeirantes.

Acreditamos, portanto, que a garantia do direito ao lazer não está baseada somente no tempo para experienciar tal dimensão, mas depende também tanto do acesso à educação quanto das condiçôes de acessibilidade dos espaços públicos destinados a essas experiências. Assim, tempo, atitude e espaço, quando conectados entre si, podem garantir esse direito que é de todos os cidadãos. 
Por fim, diante do contexto descrito, discutir espaços de lazer e acessibilidade significa discutir se a cidade é para todos. E essa é uma discussão que não pode mais permanecer restrita ao seleto grupo de arquitetos, urbanistas e planejadores detentores do saber técnico. Essa é uma problemática que impóe discutir qual cidade e sociedade se deseja. Portanto, um bom espaço de lazer deve presumir o direito à cidade, o direito à vida urbana, ao "habitar" em seu sentido amplo, em que seja dado aos usuários o direito a participar e interagir.

\section{Referências}

ALVES-MAZZOTTI, A. J.; GEWANDSZNAJDER, F. O Método nas Ciências Naturais e Sociais: pesquisa quantitativa e qualitativa. São Paulo: Pioneira Thomson Learning, 2004.

ARAUJO, C. D.; CÂNDIDO, D. R. C.; LEITE, M. F. Espaços públicos de lazer: um olhar sobre a acessibilidade para portadores de necessidades especiais. Licere, Belo Horizonte, v. 12, n. 4, p. 1-23, 2009.

ASSOCIAÇÃO BRASILEIRA DE NORMAS TÉCNICAS - ABNT. NBR 9050: Acessibilidade a Edificaçóes, Espaço, Mobiliário e Equipamento Urbano. 2. ed. Rio de Janeiro: ABNT, 2004. Disponível em: <http://www.mpdft.gov.br/sicorde/NBR9050-31052004. PDF $>$. Acesso em: 1 out. 2010.

BACIL, M. K.; WATZLAWICK, L. F. Análise da acessibilidade de pessoas com mobilidade reduzida no Parque Aquático, Irati-PR. Revista Eletrônica Lato Sensu, Guarapuava, v. 2, n. 1, 2007. Disponível em: <http:// www.unicentro.br>. Acesso em: 12 dez. 2009.

BARTALOTTI, C. C. Inclusão social das pessoas com deficiência: utopia ou possibilidade? São Paulo: Paulus, 2006.

BORJA, J. La ciudad conquistada. Madrid: Alianza Ensayo, 2005.

BRASIL. Decreto no 5.296 de 2 de dezembro de 2004. Regulamenta as Leis ${ }^{\text {os }} 10.048$, de 8 de novembro de 2000 , que dá prioridade de atendimento às pessoas que especifica, e 10.098, de 19 de dezembro de 2000, que estabelece normas gerais e critérios básicos para a promoção $\mathrm{da}$ acessibilidade das pessoas portadoras de deficiência ou com mobilidade reduzida, e dá outras providências. Diário Oficial da República Federativa do Brasil, Brasília, 03 dez. 2004. Seção 1. Disponível em: <http://www. planalto.gov.br/ccivil/_ato2004-2006/2004/decreto/ d5296.htm>. Acesso em: 3 out. 2008.

BURJATO, A. L. P. F. Parques acessiveis - um direito a cidadania. Aplicação de procedimentos para avaliação do projeto implantado: o caso do Parque Villa-Lobos. 2004. 248 f. Dissertação (Mestrado em Arquitetura)-Faculdade de Arquitetura, Universidade de São Paulo, São Paulo, 2004. CAVALCANTI, A. Avaliação da recreação e Lazer. In: CAVALCANTI, A.; GALVÃO, C. Terapia Ocupacional:
Fundamentação e Prática. Rio de Janeiro: Guanabara Koogan, 2007. p. 69-72.

CASTELLANI FILHO, L. Gestão municipal e política de lazer. In: LINHALES, M. A.; ISAYAMA, H. (Orgs.). Sobre lazer e politica: maneiras de ver, maneiras de fazer. Belo Horizonte: Editora UFMG, 2006. p. 119-135.

CONSENZA, I. F.; RESENDE, A. P. C. A Cidade e as pessoas com Deficiência: barreiras e caminhos. Sociedade \& Natureza, Uberlândia, v. 18, n. 35, p. 23-24, 2006.

CURITIBA. Prefeitura Municipal. Curitiba dobra indice de acessibilidade no transporte. Disponível em: <http://www.curitiba.pr.gov.br/publico/noticia. aspx? codigo $=18883 \&$ Curitiba-dobra- $\%$ C3\%ADndice-deacessibilidade-no-transporte>. Acesso em: 5 maio 2010.

DUARTE, C. R.; COHEN, R. A acessibilidade como fator de construçáo do lugar. In: ORNSTEIN, S. W.; ALMEIDA PRADO, A. R.; LOPES, M. E. (Orgs.). Desenho Universal: caminhos da acessibilidade no Brasil. São Paulo: Annablume, 2010. p. 81-94.

FLICK, U. Desenho da pesquisa qualitativa. Porto Alegre: Artmed, 2009a.

FLICK, U. Introdução à Pesquisa Qualitativa. 3. ed. Porto Alegre: Artmed, 2009b.

GIL, A. C. Métodos e Técnicas de Pesquisa Social. 5. ed. São Paulo: Atlas, 1999.

GOMES, C. L. Lazer, trabalho e educação: relaçôes históricas, questóes contemporâneas. 2. ed. rev. e ampl. Belo Horizonte: Editora UFMG, 2008.

HUNGER, D.; SQUARCINI, C. F. R.; PEREIRA, J. M. Pessoa portadora de deficiência física e o lazer. Revista Brasileira de Ciências do Esporte, Florianópolis, v. 25, n. 3, p. 85-100, 2004.

INSTITUTO BRASILEIRO DE GEOGRAFIA E ESTATÍSTICA - IBGE. Censo 2010. Disponível em: $<$ http://www.ibge.gov.br/cidadesat/topwindow.htm?1>. Acesso em: 12 jun. 2012.

KNOX, S. H. Tratamento através do Lazer e da Brincadeira. In: NEISTADT, M. E.; CREPEAU, E. B. (Orgs.). Willard \& Spackman - Terapia Ocupacional. 9. ed. Rio de Janeiro: Guanabara Koogan, 2002. p. 356-363.

JULIÃO, D. P.; IKEMOTO, S. M. O Direito ao lazer do deficiente visual em áreas naturais públicas e unidades de conservação. In: SEMINÁRIO ÁREAS PROTEGIDAS E INCLUSÃO SOCIAL, 2., 2006, Rio de Janeiro Anais... Rio de Janeiro: Instituto de Psicologia; Universidade Federal do Rio de Janeiro, 2006. Disponível em: <http:// www.ivt-rj.net/sapis/2006>. Acesso em: 10 mar. 2009.

LEFEBVRE, H. O Direito à Cidade. São Paulo: Centauro, 2001.

LEITE, F. P. A. O município acessivel à pessoa portadora de deficiência: $\mathrm{O}$ direito à eliminação das barreiras arquitetônicas. São Paulo: RCS Editora, 2007.

MARCELLINO, N. C. O lazer e os espaços da Cidade. In: ISAYAMA, H. F.; LINHALES, M. A. (Orgs.). Sobre lazer e politica: maneiras de ver, maneiras de fazer. Belo Horizonte: Editora UFMG, 2006. p. 65-92. 
MARCONI, M. A.; LAKATOS, E. M. Fundamentos da Metodologia Científica. 5. ed. São Paulo: Atlas, 2003.

MASCARENHAS, F. Lazer como prática de liberdade: uma proposta educativa para a juventude. 2. ed. Goiânia: UFG, 2004.

MELO, F. R. V. et al. Estudo da acessibilidade em ambientes de lazer na cidade do NATAL/RN. Licere, Belo Horizonte, v. 13, n. 2, p. 1-19, 2009. Disponível em: <http://www.anima.eefd.ufrj.br/licere/pdf/ licereV13N02_a4.pdf>. Acesso em: 20 jun. 2010.

MINISTÉRIO DAS CIDADES. Construindo a Cidade Acessível. Brasil Acessivel: Programa Brasileiro de Acessibilidade Urbana. Brasília: SEMOB, 2006. (Caderno, n. 2).

MORAES, M. C. de. Acessibilidade no Brasil: Análise da NBR 9050. 2007. 166 f. Dissertação (Mestrado em Arquitetura e Urbanismo)-Universidade Federal de Santa Catarina, Florianópolis, 2007.

NEGT, O. Espaço Público e experiência. In: PALLAMIN, V. M.; LUDEMANN, M. (Coords.). Cidade e cultura. São Paulo: Estação Liberdade, 2002. p. 5-30.

RECHIA, S. Parques públicos de Curitiba: a relação cidade-natureza nas experiências de lazer. 2003. 189 f. Tese (Doutorado em Educação Física)-Universidade Estadual de Campinas, Campinas, 2003.

RECHIA, S. Planejamento dos espaços e equipamentos de lazer das cidades: uma questão de saúde urbana. In: FRAGA, A. et al. (Orgs.). Políticas de lazer e saúde em espaços urbanos. Porto Alegre: Genese, 2009. v. 1, p. 1-125.

RECHIA, S. Curitiba Cidade-Jardim: a relação entre espaços públicos e natureza no âmbito das experiências do lazer e do esporte. Revista Brasileira de Ciências do Esporte, Campinas, v. 28, n. 3, p. 89-107, maio 2007.

RECHIA, S.; BETRÁN, J. O. Parques urbanos de Barcelona: a relaçáo entre a diversidade nas formas de apropriação e a segurança a partir de usos principais e combinados. Movimento, Porto Alegre, v. 16, n. 3, p. 181-202, 2010.

REIS, A. T. L.; LAY, M. C. D. Percepção e Análise dos Espaços - Desenho Universal. In: ORNSTEIN, S. W.; ALMEIDA PRADO, A. R.; LOPES, M. E. (Orgs.). Desenho Universal: caminhos da acessibilidade no Brasil. São Paulo: Annablume, 2010. p. 105-116.

REIS, L. J. A.; STAREPRAVO, F. A. Políticas Públicas para o Lazer: pontos de vista de alguns teóricos do Lazer no Brasil. Licere, Belo Horizonte, v. 11, n. 2, p. 1-20, 2008.

RESENDE, A. P. C. Todos na Cidade - O direito a acessibilidade das pessoas com deficiência física em Uberlândia. Uberlândia: Edufu, 2004.

REZENDE, M. B. et al. Brinquedos de parques públicos em Belo horizonte: Levantamento da acessibilidade e segurança para a criança com mobilidade reduzida. In: CONGRESSO DE TERAPIA OCUPACIONAL, 5., 2007, Goiânia. Anais... Goiânia: Associação dos Terapeutas Ocupacionais de Goiás, 2007. CD-ROM.

RIBEIRO, N. M. S. et al. Análise do ambiente de lazer para portadores de deficiência física com alteração na locomoção na cidade de Salvador. Diálogos Possiveis, Salvador, v. 6, n. 1, p. 233-242, jan./jun. 2007. Disponível em: <http://www.faculdadesocial.edu.br/dialogospossiveis/ artigos/10/17.pdf>. Acesso em: 25/9/2009.

SANTOS, A. et al. Lazer, Esporte, Jogo e Trabalho: uma relação com a deficiência. Diálogos Possivveis, Salvador, v. 5, n. 1, p. 173-187, jan./jun. 2006. Disponível em: <http://www.fsba.edu.br/dialogospossiveis>. Acesso em: 20 ago. 2008.

ZUCHETTO, Â. T.; CASTRO, R. L. V. G. de. As contribuiçóes das atividades físicas para a qualidade de vida dos deficientes físicos. Revista Kinesis, Santa Maria, v. 26, p. 52-166, 2002.

\section{Contribuição dos Autores}

As autoras trabalharam em conjunto em todas as etapas da produção deste artigo.

\section{Notas}

${ }^{1} \mathrm{O}$ texto apresentado é parte de dissertação de mestrado defendida no Programa de Pós-Graduação em Educação Física da UFPR. Foi aprovado pelo Comitê de Ética em Pesquisa em Seres Humanos do Setor de Ciências da Saúde da UFPR sob n. 973.098.10.0.

${ }^{2}$ Várias expressốes referem-se às pessoas com deficiência. Na área da Educação, as expressôes "pessoas com necessidades especiais" ou "pessoas portadoras de necessidades especiais", na legislaçấo brasileira, "portadores de deficiência”, porém neste trabalho será utilizada a expressão "pessoa com deficiência”, por ser a adotada pela Convenção Internacional sobre os Direitos da Pessoa com Deficiência, aprovada pela Assembléia da ONU em 2006.

${ }^{3}$ De acordo com o decreto n. 5.296/2004, pessoa com mobilidade reduzida é aquela possui dificuldade de movimentar-se, permanente ou temporariamente, gerando redução efetiva da mobilidade, flexibilidade, coordenação motora e percepção.

${ }^{4}$ DISCHINGER, M.; ELY, V. H. M. B.; MACHADO, R.; SILVA, R. M. de S.; PADARATZ, R.; ANTONINI, C.; DAUFENBACH, K.; SOUZA, T. R. M. de. Desenho Universal nas escolas: acessibilidade na rede municipal de ensino 
de Florianópolis. Florianópolis: Grupo PET Arquitetura e Urbanismo, UFSC: Prefeitura Municipal de Florianópolis, 2004.

${ }_{5}^{5}$ O Plano Urbanístico Agache foi desenvolvido pelo arquiteto francês Alfred Agache. Disponível em: <http://www. casadamemoria.org.br/index_historiadecuritiba.html>. Acesso em: 9 jan. de 2011.

${ }^{6}$ Rechia (2007) pontua a relação entre planejamento urbano e poder público na criação da marca identitária. Também afirma que a busca de uma marca identitária tem sido objeto de disputa entre as cidades para conseguirem atrair mais pessoas e investimentos, o que sugere uma visão da cidade com valor de troca.

${ }^{7}$ Lei n. 11.266, de 16 de dezembro de 2004. Dispóe sobre a adequação do Plano Diretor de Curitiba ao Estatuto da Cidade. O Plano Diretor de Curitiba foi instituído pela lei n. 2.828, de 10 de agosto de 1966.

${ }^{8}$ MOURA, R. O turismo no projeto de internacionalização da imagem de Curitiba. Revista Turismo - Visão e Ação, v. 9 , n. 3, set./dez. 2007.

${ }^{9}$ Dados referentes a pessoas com deficiência motora leve, moderada e grave apresentados no censo de 2010 do IBGE.

${ }^{10} \mathrm{O}$ grupo A Uniāo faz a Força é um grupo de pessoas cadeirantes formado em 2008 em um Centro de Referência de Assistência Social (Cras) de Curitiba sob a coordenação de uma terapeuta ocupacional. Tem como objetivo discutir questóes relacionadas à inclusấo e à acessibilidade nas atividades culturais e de lazer. Atualmente é um grupo voluntário e independente.

${ }^{11}$ Esse roteiro foi baseado na Norma Brasileira de Acessibilidade (NBR-9050) e no Protocolo de Acessibilidade do CREA-PR, porém foi delimitado para as questôes relacionadas às pessoas com deficiência física ou mobilidade reduzida. Não foram consideradas as determinaçóes da NBR 9050 voltadas para as pessoas com deficiência visual, auditiva ou intelectual.

${ }^{12} \mathrm{O}$ método "passeio acompanhado" foi desenvolvido por Dischinger (2000) e permite observar a realidade do usuário no uso do espaço. É utilizado para se ter uma visão precisa da realidade e para avaliar as condiçóes de acessibilidade. No passeio são utilizados gravadores e máquinas fotográficas (GUIMARÁES, E. A. et al. Passeios acompanhados - Método investigativo de leitura e compreensão do espaço construído através de interface usuário-pesquisador. In: 60 Ergodesign, Bauru, 2006. Disponível em: <http://www.arq.ufsc.br/petarq/wp-content/uploads/2008/02/ergodesign-13.pdf>. Acessado em: 9 out. 2010. Nesta pesquisa utilizamos a filmagem e a fotografia como recursos no passeio acompanhado.

${ }^{13}$ Observação do passeio realizado pelo grupo A União faz a Força em 19 de outubro de 2010.

${ }^{14}$ Observação do passeio realizado pelo grupo A União faz a Força em 7 de maio de 2010. 